clusion seems to me to be justified that, so far as we have gone and, as far as I can learn, so far as others have gone with this process, its excessive cost and sensitiveness or lack of reliability are such that the engineer is not warranted in recommending it for general adoption except where special conditions control.

1013 Mechanics Bank Building

BROOKLYN, NEW YORK

\section{ACTIVATED-SLUDGE EXPERIMENTS AT THE SEWAGE DISPOSAL PLANT, BALTIMORE}

By Calvin W. Hendrick

Chief Engineer, Department of Public Improvement, Baltimore

Work on activated-sludge experiments began during late winter. After developing ideas for general operation of a converted Imhoff tank along the continuous-flow activated-sludge method the first question to decide was the selection of suitable porous material, through which air in small bubbles was to be admitted to the mixture of sewage and sludge. Experiments were conducted in an iron cylinder to determine the necessary pressure and the volume of air passed through various types of porous material. Carborundum, alundum, sand and cement, filtros, and unglazed tile were the materials tested, specimen samples having been furnished by the various manufacturers. The apparatus consisted of an iron cylinder, flanged at each end, with plate glass to allow easy inspection. Inside the cylinder a disc of the material, 3 in. $X$ I in., was clamped to a recessed flange, which in turn was attached to a compressed-air container. Mercury tubes and valves were arranged to measure the pressure and to regulate the volume of air. Water was put into the iron cylinder to cover the disc in order that some idea could be obtained regarding the size of air bubbles. When air was admitted to the fiange it escaped by passing through the porous disc in small bubbles. Pressures, both pre-disc and postdisc, were maintained, equaling those in the bottom of the converted Imhoff tank. A record was kept of the pressures necessary and the volumes of air passing through the disc, and curves were drawn.

The cement and unglazed tile discs broke on being clamped to the flange and were eliminated because of their unreliable strength. The filtros tile needed but a few inches of head to force air through it but was discarded because the bubbles emitted were too large. Both carborundum and alundum were acceptable because of the smallness of the bubbles, but carborundum dises are less expensive. It was necessary to exert greater pressure on carborundun than on filtros, but the great advantage of having very small bubbles, thereby giving a larger contact per unit volume, is more important.

Five 4-liter bottles nearly filled with various mixtures of sewage and sludge were aerated from March 3 to about June Io. The information sought was to determine the mixture that produced most quickly an activated sludge, the rate at which the sewage could be purified, and the composition and other features of the sludge itself.

The tests made May 17, I9I5, give an idea of the purification obtained under this laboratory method of aeration: the results are expressed in parts per million.

\begin{tabular}{|c|c|c|c|c|c|}
\hline No. & $\begin{array}{l}\text { CONTENTS OF } \\
\text { Per cent sludge }\end{array}$ & $\begin{array}{l}\text { BOTTLES } \\
\text { Balance }\end{array}$ & $\begin{array}{l}\text { AMMONIA } \\
\text { NITROGEN }\end{array}$ & $\begin{array}{l}\text { NITRATE } \\
\text { NITROGEN }\end{array}$ & $\begin{array}{l}\text { DISSOLVED } \\
\text { OXYGEN } \\
\text { CONSUMED }\end{array}$ \\
\hline $\begin{array}{l}1 \\
2 \\
3 \\
4 \\
5\end{array}$ & $\begin{array}{l}20 \text { (settling basin) } \\
\text { None } \\
20 \text { (settling basin) } \\
20 \text { (settling basin) } \\
20 \text { (hydro tank) }\end{array}$ & $\left\{\begin{array}{l}\text { Raw sewage } \\
\text { Raw sewage } \\
\text { Filter effluent } \\
\text { Very fresh sewage } \\
\text { Raw sewage }\end{array}\right.$ & $\begin{array}{l}0.9 \\
0.2 \\
0.8 \\
0.5 \\
0.3\end{array}$ & $\begin{array}{l}6.2 \\
3.0 \\
2.6 \\
9.8 \\
7.2\end{array}$ & $\begin{array}{l}0.6 \\
0.8 \\
0.5 \\
2.0\end{array}$ \\
\hline
\end{tabular}

The supernatant liquid was drawn from Bottles I, 3 and 4 four times a day, and from 2 and 5 twice a week. Samples $\mathrm{I}$, 3 and 4 produced activated sludge within 3 wks., but the fresh sludge from the hydro tank needed about $6 \mathrm{wks}$. to become activated. This tended to prove that the sludge or humus from the sprinkling filters has characteristics somewhat similar to activated sludge.
Bottle 3 was covered, May I4, with a cloth to exclude light absolutely in order to render conditions similar to those at the bottom of a large tank. Subsequent analysis showed that the absence of light had no noticeable effect on the activated-sludge organisms.

A sample of sludge taken from Bottle I, May I3, had a total nitrogen content on a dry basis of 4.39 per cent, which is a higher figure than any determined on our ordinary sludge and more than twice as high as the average ritrogen content of ordinary digestion-tank sludge. The low average figures for nitrate nitrogen in the effluent apparently show that most of the nitrogen in all forms stays in the sludge. This, of course, makes it more valuable as a fertilizer. The first English experiments last year showed that sludge produced by this method contained about three times as much nitrogen as did ordinary sludge.

During the spring, work was done in arranging Imhoff Tank 3 for operation on a continuous-flow activated-sludge basis. A series of pipes leading to 79 discs of No. I 20 grit carborundum 6 in. $X I$ in. were laid on the hopper bottom of the tank and connection was made by a 2 -in. down pipe to a Hollingsworth blower, belt-driven by a motor. The tops of all the discs were brought as near as possible into the same horizontal plane. Sludge from the settling basins was dumped into the tank and air was pumped continuously into the mixture of sludge and raw sewage after August 5. A I2-in. iron pipe set upright and filled with graded gravel, over which clean water was sprayed, was placed in the air line between the blower and the porous discs. The air passed upward through the gravel, and the apparatus was designed to clean the air of any particles of dust or oil vapor from the blower.

Aeration was continued with the original loading of sludge and sewage till August I7, when raw sewage was allowed to flow for two days continuously through the tank. About 0.25 second-foot of sewage probably passed through. In this short time the effluent went back to its raw state showing that the sludge had lost its ability to purify. The flow of sewage was stopped and more sludge was at once dumped into the tank till a sludge ratio of about 30 per cent was attained. No more raw sewage was allowed to enter the tank till September 20, when a small stream was continuously passed through with a stream of purified sewage. The air has been roughly measured at about 5 volumes per volume of raw sewage. The operation has remained the same to date.

It was found necessary to agitate the sludge which settled underneath the grid of porous discs. This was done by putting a $\mathrm{I}$-in. pipe down the sludge pipe and attaching it to the flushingwater system. The purified sewage, from this system traveling at high velocity, tends to stir up the settled sludge, which otherwise would become septic and create conditions unfavorable to the life and increase of activated-sludge organisms. It is hoped that this agitation may be discontinued when the inflowing raw sewage has been increased to such volume that it is itself capable of performing the necessary agitation. Whether this purified sewage has a good or a bad effect on the effluent is uncertain. The effluent from the tank is now clear and sparkling. A sample taken October 4 has the following constituents:

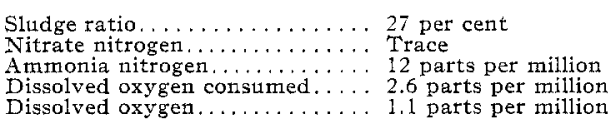

The low figure of dissolved oxygen consumed indicates that no nuisance would occur by running an effluent of this character into a small stream. At the present slow rate of flow the raw sewage has an oxidation and sedimentation period of about 24 hrs., equivalent to a total tank replacement once a day. It is intended to increase gradually the rate of flow till a maximum is obtained. 
Much trouble has been experienced with the present method of introducing air into the sewage. It seems impossible to prevent oil from passing over with the air to the lower side of the porous dises where it forms a film which increases greatly the resistance to the passage of air through the material. The carborundum is very finely divided and is easily choked up, which detracts greatly from its other advantages as part of a permanent installation. As the oil collects the air pressure increases and less air escapes through the discs because of greater slippage in the blower. The increasing resistance to passage through the discs acts in the same manner as the closing of a valve does on a stream of water. This serious difficulty is being considered with care. A limit to the air supply limits the amount of raw sewage that may be passed through the tank, and, until the proper flow is determined, an elastic air system covering wide variation of volume is necessary.

The air washer has been rearranged several times with negligible improvement. It may become necessary to replace the carborundum discs with more porons ones like filtros. This, of course, loses to the equipment the advantage of producing very small air particles, but the first and most important consideration is to put the operation on a sound working basis, which cannot be done, seemingly, with the present discs.

It was originally decided to conduct experiments in another tank aerated by a propeller enclosed in a draft tube, but it was found impracticable to run both experiments at the same time.

Laboratory analyses and physical observations on the action of the experiments have developed to a great extent our knowledge of this form of sewage purification, but we feel, in order that the final conclusions may have value, that no pains should be spared to know exactly and make a record of each step and change in everything pertaining to the experiment. The temperature of inflowing and outflowing raw sewage, the temperature of the atmosphere and the compressed air, and rate of sewage flow are recorded every hour. The rate of air supply will be recorded after the air meter has been installed.

We have already proved that it is possible to purify sewage by an activated-sludge method and that operation may be made continuous. It remains to determine the rate at which sewage can be purified and the total cost of operation.

DePartMent of PUBlic Improvements BALTIMORE

\section{COMPOSITION OF THE EFFLUENT AIR FROM AN ACTI- VATED-SLUDGE TANK}

By $F . X$. Crawford and Eldward Bartow

Graduate Student, Chemistry Department, and Director of Illinois Water Survey

The remarkable purification effected by aeration in the presence of activated sludge indicates that air plays an important rôle in the process. As an increase in the content of carbon dioxide and a decrease in the content of oxygen of the effluent air were expected, determinations of those two constituents of the effuent air from tanks at an experimental plant treating domestic sewage at the University of Illinois were made from January to April, igI6. Carbon dioxide was determined according to the method of Hesse with an accuracy between one and two parts per 10,000 . The air was measured over water in an unjacketed Winkler burette, and its content of oxygen was determined by absorption in alkaline pyrogallol in a Hempel double absorption pipette for liquid reagents with an accuracy between 0.2 and 0.3 per cent; no corrections were made for temperature or pressure.

The influent air, obtained from the compressed-air supply of the University, was measured by a common gas meter at about $5 \mathrm{lbs}$. more than atmospheric pressure. The effluent air was collected in Erlenmeyer flasks of $500-$ to $800-c c$. capacity by displacement of the medium through which the air passed, no chance for outside contamination thus being afforded. The carbon dioxide was determined in the flask in which it was collected. The compressed air, according to numerous analyses, has substantially the same composition as the atmosphere, containing 4.3 parts per 10,000 of carbon dioxide and 20.5 per cent of oxygen.

Aeration was carried on according to a regular schedule, each aeration period occupying 5 hrs. Hourly samples were generally taken, or 6 samples for each aeration period. An initial decline in the amount of catbon dioxide blown out usually occurs at the beginning of the aeration period. A marked increase usually follows this decline though the final amounts are not always the highest. These variations are illustrated by the results of the first five series of tests in the accompanying table of representative data. Some analyses showed an increase from beginning as indicated in the sixth series. The average flow of air into 400 gal. of sewage was $187 \mathrm{cu}$. ft. an hour at atmospheric pressure.

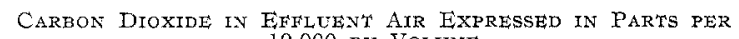

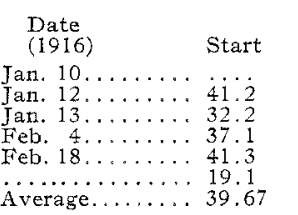
10,000 BY VOLUME

$\begin{array}{rllll}1 \text { hr. } & 2 \text { hrs. } & 3 \text { hrs. } & 4 \text { hrs. } & 5 \text { hrs. } \\ 32.4 & 30.8 & 38.4 & 40.0 & 45.6 \\ 33.0 & 37.2 & 44.2 & 36.8 & 50.6 \\ 29.2 & 37.2 & 38.0 & 39.8 & 37.6 \\ 36.6 & 33.9 & 37.1 & 38.8 & 42.2 \\ 38.3 & 37.0 & 38.3 & 43.5 & 46.0 \\ 26.8 & 33.6 & 31.0 & 42.0 & 66.8 \\ 37.5 & 36.41 & 38.02 & 38.94 & 39.42\end{array}$

The rate of flow of air has little relation to the amount of carbon dioxide in the effluent air; with an average flow of 240 cu. $\mathrm{ft}$. an hour the content of carbon dioxide was 45.6 and 66.8 parts per 10,000, whereas at another time, with an inflow of only $89 \mathrm{cu}$. ft. an hour, the content was as much as 50.6 parts per ro,, 00 . During an aeration period, while the tank was filled with sewage and no sludge, the content of carbon dioxide was highest at the beginning, dropping from 14.2 to 8.6 parts per 10,000 . During another, on the second day after sludge had begun to accumulate the contents of carbon dioxide at the beginning and the end were substantially alike, 19.7 and 20.8 parts per 10,000 .

When the content of carbon dioxide increased, the content of oxygen of the effluent air was I.O to I. 2 per cent less than that of the influent air. The effluent air contained I9.3 to I9.5 per cent of oxygen; that is, about 5 per cent of the oxygen in the air was used in the process. The increase of carbon dioxide probably could not take place by simple oxidation of carbonaceous matter without bacterial action. It was believed that some of the carbon dioxide might be dissolved in the sewage; that the initial decrease in content of carbon dioxide of the effuent air was due to loss of dissolved carbon dioxide was proved by aerating tap water under conditions similar to those under which sewage was aerated.

When tap water in a tank was aerated the temperature remained constant throughout the aeration period, but the content of dissolved carbon dioxide rapidly decreased as shown by tests of half-hour samples. The general average content at the start in three experiments was 22.8 , at the end of $\mathrm{I} \mathrm{hr}$. I4. I, at the end of 2 hrs. 6.5 , and at the end of $21 / 2$ to 3 hrs. it became 0.0 . The disappearance of dissolved carbon dioxide was quickly followed by an alkalinity in presence of phenolphthalein, which slowly increased to 26 to 32 parts per million at the end of the aeration periods. The total alkalinity, about 350 parts per million, remained practically constant in the experiments. The average content of carbon dioxide of the effluent air at the beginning of aeration was,30 parts per 10,000 , and it decreased steadily throughout aeration though it decreased to the amount normally present in the atmosphere in only one experiment. The average content of oxygen of the effluent air at the start was 19.6 per cent, but before the end of aeration the amount normally in the atmosphere. 20.5 